La artesanía en Andalucía 04

\title{
Carpintería de ribera, una cultura vinculada a la pesca
}

Alfonso Sánchez Guitard López Valera. Vocal de Cultura de la Asociación de Vecinos de los Baños del Carmen (Málaga)

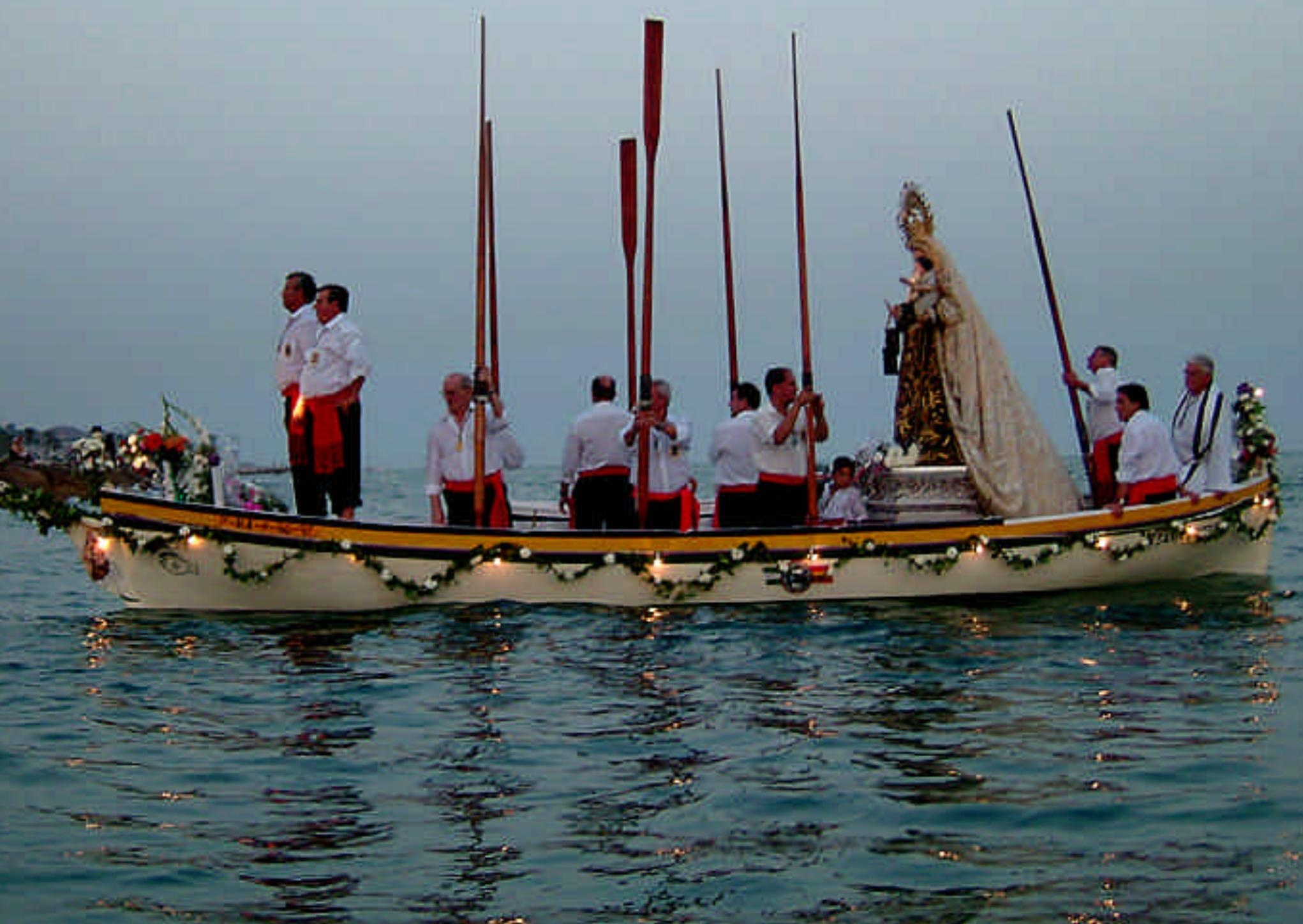




\section{Se han dignificado unos oficios y las vidas de unas personas normalmente olvidadas por la administración}

La carpintería de ribera en Andalucía es una actividad documentada desde hace miles de años. Prueba de ello son las pinturas rupestres de Jimena de la Frontera en Cádiz, donde aparecen dibujadas una serie de embarcaciones y hasta lo que se ha interpretado como un astillero, o en los innumerables testimonios fenicios que hay repartidos por las costas andaluzas o las riberas del Guadalquivir.

Desde tiempo inmemorial, por tanto, se han desarrollado en las costas y ríos de Andalucía unos usos y costumbres directamente relacionados con el aprovechamiento de los recursos marinos y fluviales, mediante la pesca y las actividades económicas que generaba. En este contexto, el barco aparece para aprovechar mejor esos recursos, así como medio de transporte e intercambio cultural. Estos modos de vida subsisten aún en pequeños pueblos y barrios de pescadores que como señas de identidad sintetizan los medios de subsistencia con unos rituales colectivos típicamente andaluces. Tal es el caso del barrio de pescadores del Pedregalejo (Málaga) y del municipio sevillano de Coria del Río

En otoño de 2003 la Dirección General de Bienes Culturales de la Junta de Andalucía decide proteger como Actividad de Interés Etnológico la carpintería de ribera en Coria del Río (Resolución 12 de septiembre de 2003 de la Dirección General de Bienes Culturales), comenzando una nueva línea de protección para su inscripción en el Catálogo General del Patrimonio Histórico Andaluz (CGPHA). Dicha actividad hunde sus orígenes en la más remota antigüedad, y es un oficio que junto a muchos otros desaparecidos o en vía de desaparición ha estado ligado al río Guadalquivir. El Ayuntamiento de Coria del Río, cumpliendo con el mandato legal de poner en valor los bienes del

- Procesión de la Virgen del Carmen en Pedregalejo (Málaga) / Francisco Sánchez Guitard patrimonio histórico que radican en su término municipal, ha creado un equipamiento cultural dotando al municipio de una escuela taller de carpintería de ribera con la que recuperar la barca coriana, soporte de las actividades económicas generadas por la pesca del albur y del esturión. También ha diseñado un museo etnográfico para difundir no sólo la importancia de la carpintería de ribera, sino toda una serie de elementos culturales y tecnológicos relacionados con los modos de vida de las gentes que durante siglos utilizaron los recursos del río Guadalquivir como forma de subsistencia

Pensemos en la importancia de la explotación del esturión desde época antigua, donde se llegó a acuñar una moneda, la de caura, adornada con dos peces: un sábalo o un esturión. Incluso hoy en día están replanteándose formas de resignificar el uso de estas señeras embarcaciones por parte de los técnicos de cultura del Ayuntamiento de Coria para emplearlas en competiciones deportivas, como se hace en Málaga con las barcas de jábega .

El caso de Pedregalejo guarda muchas similitudes respecto al anterior. Pedregalejo es un pequeño barrio de pescadores donde se tiene constancia histórica de la existencia de asentamientos humanos vinculados al mar desde hace siglos. En sus alrededores hay yacimientos que datan del paleolítico, en el que la actividad de la pesca era parte fundamental de los modos de subsistencia de sus moradores. Hoy en día este barrio está siendo víctima de la presión urbanística al estar en una zona residencial con gran especulación. En dicho barrio aún perduran actividades como la pesca artesanal, que se mantiene gracias a personas de cierta edad que aún viven de ella o que la continúan practicando como vía para reafirmar su identidad, y la carpintería de ribera de los Astilleros Nereo, cuyos maestros conservan vivos los moldes tradicionales de dicha actividad desde tiempos remotos. 


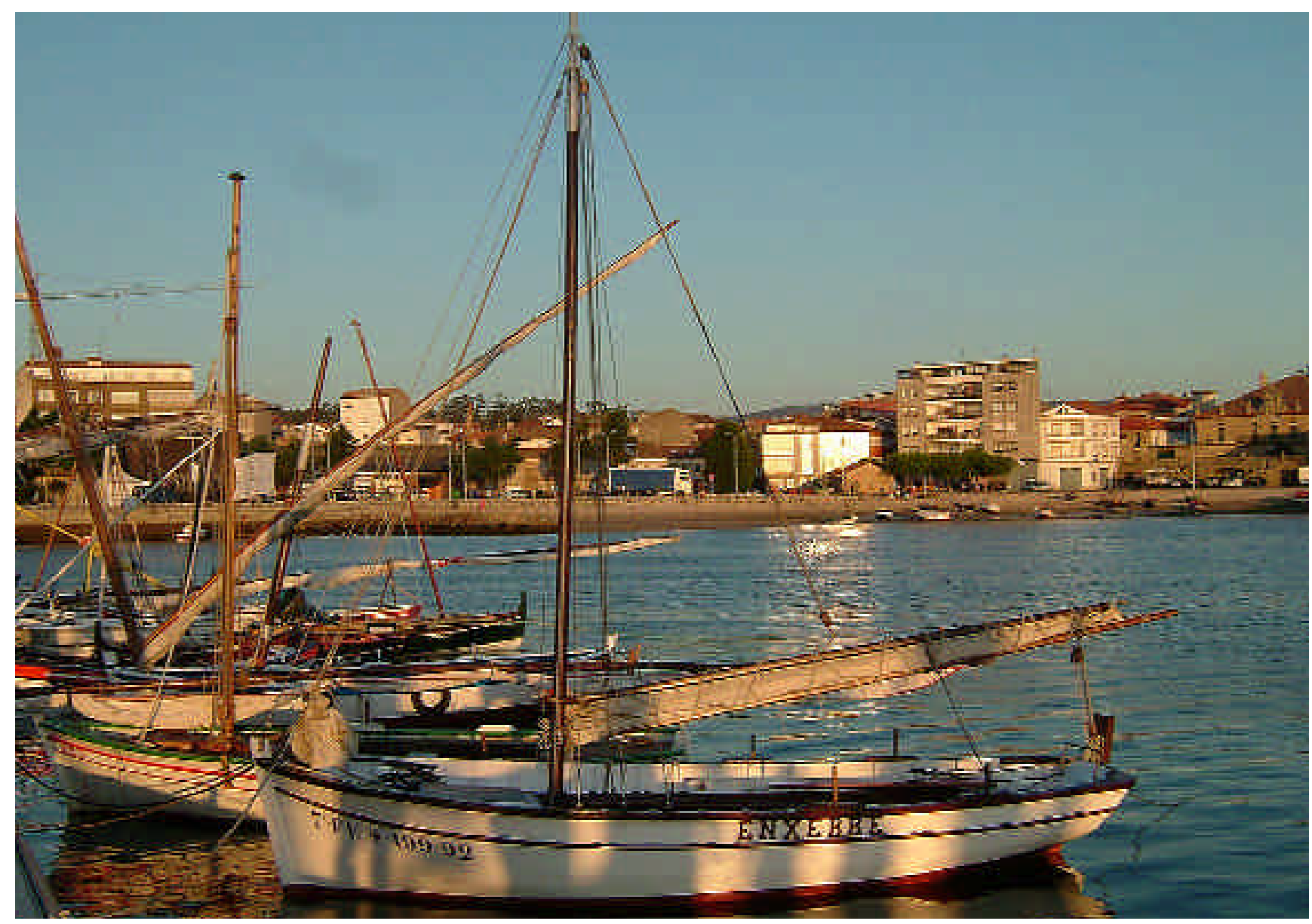

- Encuentro etnográfico de la cultura marítima y fluvial de la Península Ibérica en Cambados (Pontevedra, Galicia) /

Francisco Sánchez Guitard 
En este barrio se da la peculiaridad de contar con varias asociaciones ciudadanas comprometidas en la tarea de salvaguardar y enriquecer este patrimonio vivo, y con la labor de mecenazgo cultural realizada por los mismos astilleros relacionada con la recuperación de embarcaciones tradicionales.

En diciembre de 2003 estas asociaciones se unieron para formar la Plataforma ciudadana para la protección de la carpintería de ribera de Astilleros Nereo y pedir a la Junta de Andalucía su protección. Con la incoación del expediente de catalogación en el CGPHA como Actividad de Interés Etnológico de la carpintería de ribera de Astilleros Nereo e 21 de marzo de 2005, la Administración Andaluza daba respuesta a dicha petición (Boja nº 74 de 21 de marzo de 2005).

Hoy, dos años después, y como consecuencia de esa actuación, las carpinterías de ribera de Andalucía se están conociendo entre sí y estableciendo lazos fraternos de colaboración ciudadana e institucional y, en torno a ellas, el resto del patrimonio inmaterial relacionado con la cultura marítima y fluvial de Andalucía. De esta manera, y sin haberse cumplido un mes de la incoación del expediente de la carpintería de ribera de Astilleros Nereo, Málaga y Sevilla se unían a través de su patrimonio cultural mediante un hermanamiento entre los carpinteros de ribera de Coria y los de Pedregalejo, que fue difundido por los medios de comunicación. Con dicho hermanamiento se han creado unos vínculos humanos no sólo entre los maestros, sino también entre las poblaciones de Coria y de Pedregalejo, que a fecha de hoy se ha plasmado en la creación de la Federación Andaluza por la Cultura y el Patrimonio Marítimo y Fluvial (www.patrimoniovivo.com), con la que Andalucía ha entrado de lleno en la órbita del movimiento y compromiso ciudadano de todas las comunidades marítimas de España que gira en torno a la salvaguarda, puesta en valor, enriquecimiento, difusión y protección de su patrimonio inmaterial relacionado con sus modos de vida: folclore, oficios, artesanía, gastronomía, que en determinados núcleos humanos del mar o ribera de ríos aún subsisten como patrimonio vivo.

Además, el pasado verano (2005), en Cambados, la Federación Andaluza, representada por la Barca de Jábega Rosario y Ana y sus jabegotes, junto con la catalana y la gallega, con motivo del encuentro de embarcaciones tradicionales, crearon la Confederación de la Cultura Marítima y Fluvial, para dar una respuesta común a este sentir. La Confederación pretende solicitar a la UNESCO la declaración de este patrimonio inmaterial de la Península Ibérica como patrimonio de la humanidad, entre otros muchos fines, que se pueden resumir en la lucha por la defensa de los elementos culturales que aún subsisten a lo largo de toda la costa peninsular y de la ribera de sus ríos, así como de los modos de vida de las personas que los mantienen vivos.

Aunque Galicia y otros lugares de España, como Cataluña y el País Vasco, llevan años trabajando en este sentido, y la conciencia sobre

\section{Las consecuencias más importantes derivadas de la protección de este tipo de patrimonio se producen a nivel humano y social}

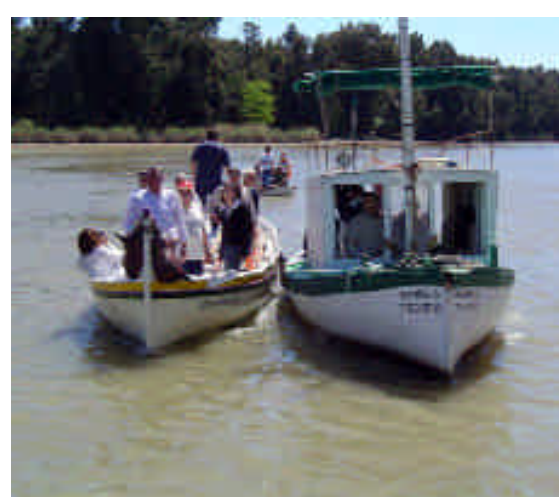

(1) Hermanamiento de Coria / Francisco Sánchez Guitard

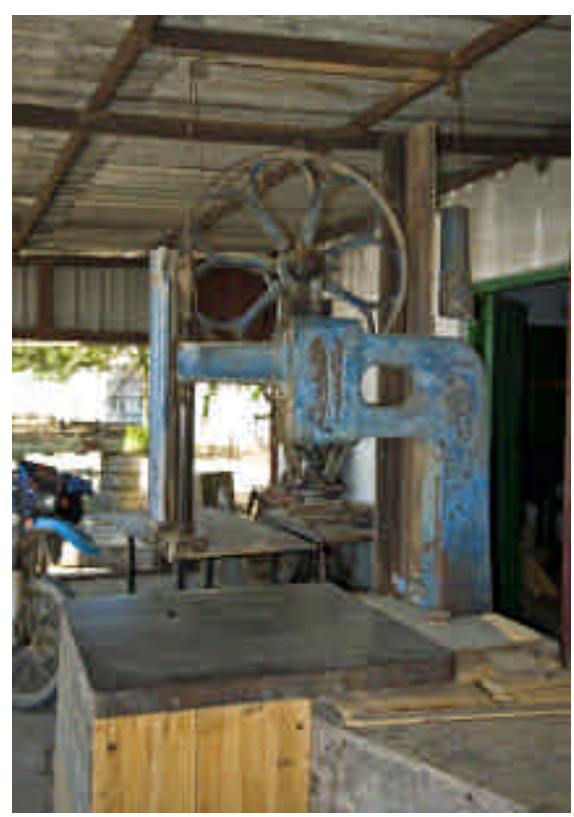

(1) Interior del taller de Carpintería de Ribera de Coria del Río (Sevilla) / Javier Romero, IAPH 


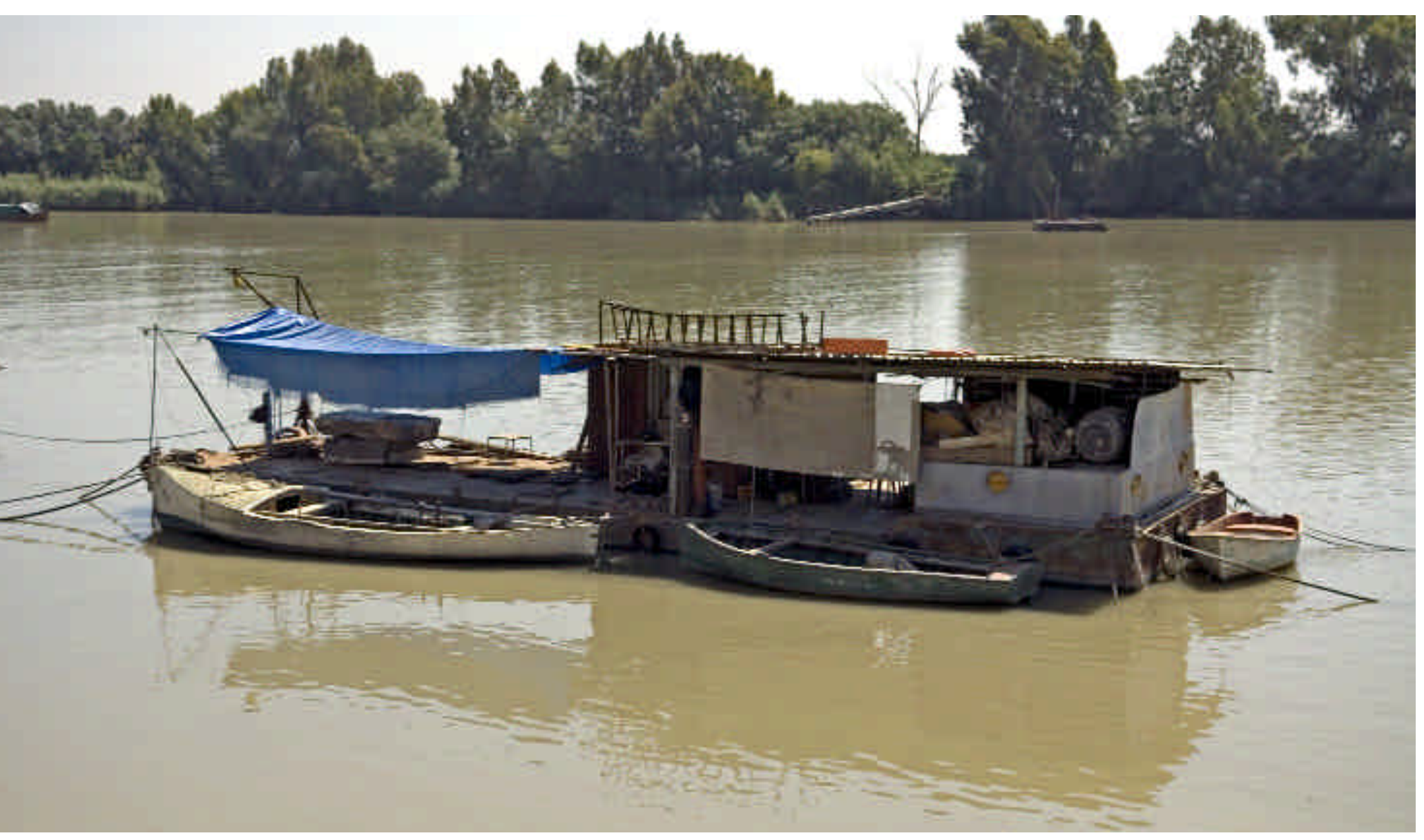

( ) Ribera de Coria del Río

(Sevilla) / Javier Romero, IAPH 
este patrimonio está muy enraizada entre las asociaciones, colegios, medios de comunicación, etc., Andalucía lleva la delantera claramente en cuanto a protección administrativa se refiere, pues si bien es cierto que, por ejemplo, en Galicia la carpintería de ribera está muy viva con programas de Escuelas Taller apoyadas por pequeños municipios, con los que se recuperan embarcaciones tradicionales y se da trabajo a numerosas personas, esta realidad no está acompañada con la correspondiente tutela jurídico-administrativa por parte de la administración competente. Por su parte, la Generalitat está estudiando qué elementos culturales tienen valor patrimonial y sus representantes ciudadanos quedaron muy interesados de los pasos dados de forma tan precisa por la Junta de Andalucía en materia de política cultural.

Como reflejo de estos lazos creados entre las distintas comunidades marineras, hay que mencionar la visita realizada por los máximos representantes del Ayuntamiento de Coria del Río, así como del maestro de la carpintería de ribera coriana Fernando Asián, a las instalaciones que albergan la carpintería de ribera de Astilleros Nereo; visita aprovechada para comenzar una nueva construcción de barca de jábega, cuyos honores hicieron dichos representantes, y cuya cuaderna maestra realizó el mismo maestro. Esta cuaderna, a petición del presidente de la Asociación de Pescadores de Málaga Este, llevará grabado el nombre del "Hachilla" (apodo de Asián).

Otra consecuencia de la incoación de la carpintería de ribera de Astilleros Nereo para su inscripción en el CGPHA ha sido la concesión por parte de la Consejería de Empleo y Desarrollo Tecnológico de la Junta de Andalucía del programa de Formación para el Empleo relacionado con la carpintería de ribera. De esta forma se están dando los pasos para declarar las instalaciones de los Astilleros Nereo como centro colaborador de la Formación Profesional Ocupacional, y poder impartir cada año el curso de carpintería de ribera que difunde los conocimientos transmitidos por los maestros Serrano de forma tradicional. Este año, ocho alumnos, cuatro de ellos inmigrantes, han recibido el curso que, al ser impartido con compromiso de contratación, ha dado respuesta a las demandas de mano de obra cualificada tan escasa en este tipo de oficios hoy en día; y que mediante la contratación, además de continuar la formación de forma oral, participan en la recuperación y enriquecimiento del patrimonio etnográfico andaluz con la restauración de una buceta y un sardinal, embarcaciones pesqueras que durante años fueron el sustento de muchas familias, cuyo recuerdo sigue latente en los habitantes del barrio de pescadores en el que se levantan dichas instalaciones que en ocasiones acuden al taller para rememorar, a veces con nostalgia, el uso que les daban a esas embarcaciones. Además, gracias a la conciencia despertada en el personal del Astillero y asociaciones ciudadanas como consecuencia de la declaración como Patrimonio Etnográfico de Andalucía, así como por el sentir de las asociaciones que forman la

\section{Gracias a la actuación de la Consejería de Cultura, las carpinterías de ribera de Andalucía se están conociendo entre sí y estableciendo lazos fraternos de colaboración ciudadana e institucional}

Confederación Ibérica, dichas restauraciones están siendo acompañadas por los correspondientes soportes técnicos (planos, maquetas, etc.) para poder facilitar la labor de difusión y salvaguarda de la Junta de Andalucía.

Los días 22, 23 y 24 de septiembre de 2006, está previsto otro hermanamiento con los carpinteros de ribera de la provincia de Almería, que tendrá lugar en el barrio de Pedregalejo y que se prevé organizar con la intención de difundir el patrimonio etnográfico de la cultura marítima andaluza. La idea es hacer de ese día una auténtica feria etnográfica en el que participarán representantes de otras comunidades del estado como Cataluña y Galicia, que acudirán con sus embarcaciones típicas y otros elementos significativos de su cultura marinera.

Pero las consecuencias más importantes en materia de la protección de este tipo de patrimonio se están produciendo a nivel humano y social, pues ha creado en el caso de Pedregalejo una reactivación y concienciación de sus señas de identidad como barrio singular, uniendo aún más a las personas por encima de ideologías o estereotipos sociales. Se han dignificado unos oficios y en definitiva las vidas de unas personas normalmente olvidadas por la administración mediante el reconocimiento público de la importancia que tuvieron y tienen en nuestras memorias colectivas. Aún queda mucho por hacer...

\section{Bibliografía}

AZOTEA. Revista de Cultura del Ayuntamiento de Coria del Río, $n^{\circ}$ 13-14. Monográfico dedicado a El Esturión del Guadalquivir

FERNÁNDEZ DE PAZ, E. (1991) Carpintería de ribera en el Bajo Guadalquivir. Sevilla: Consejería de Cultura, 1991

TOPPER, U. ; TOPPER, V. (1988) Arte Rupestre en la provincia de Cádiz. Cádiz: Diputación Provincial, 1988 